\title{
Los casos Burlington y Perenco: Una mirada a las discrepancias ambientales en aspectos de determinación de responsabilidades y cuantificación de daños
}

Emilia Limongi Izaguirre*

César Sánchez Icaza**

Recibido/Received: 19/08/2021

Aceptado/Accepted: 17/10/2021

SumArio: 1. Introducción. 2. La sofisticada tecnicidad de las reclamaciones ambientales en los arbitrajes en derecho. 2.1. El carácter vinculante de los informes periciales. 2.2. Prevalencia del laudo posterior y sus consideraciones técnicas sobre el laudo anterior. 2.2.1. Métodos investigativos para el esclarecimiento de los hechos. 2.2.2. Formas de cuantificar el daño ambiental. 2.3. Visita in situ del Tribunal vs. Peritaje. 3. Competencia de los Tribunales para determinar responsabilidades a las partes y a terceros. 3.1. Responsabilidad subjetiva vs. responsabilidad objetiva aplicada a un mismo asunto. 3.2. Responsabilidad de terceros declarada en arbitrajes en los que no formaron parte. 4. La posibilidad de iniciar dos reclamaciones paralelas sobre lo mismo para escoger la resolución que más convenga al reclamante. $\mathbf{5}$. Conclusiones.

ReSUMEN: Las reconvenciones de Ecuador anteel Centro Internacional de Arreglo de Diferencias Relativas a Inversiones (CIADI) por daños ambientales en el territorio ecuatoriano, trajeron como resultado situaciones atípicas para la práctica arbitral: (i) planteamiento de

\footnotetext{
* Asociada Senior en Lexvalor Abogados. Abogada por la Universidad de Especialidades Espíritu Santo de Guayaquil. Correo electrónico: elimongi@lexvalor.com

** Socio en Lexvalor Abogados. Abogado por la Universidad Católica de Santiago de Guayaquil. Correo electrónico: csanchez@1exvalor.com
} 
dos reclamaciones paralelas por los mismos daños ambientales producidos en una misma zona geográfica; (ii) pretensión expresa de la reclamante de que escogería la decisión más favorable a sus intereses; (iii) aplicación de reglas distintas para establecer responsabilidades civiles; (iv) contraria valoración de los mismos informes periciales por parte de los Tribunales; (v) expedición de un laudo posterior que "complementó" el laudo anterior, en lo que respecta a la cuantificación de daños; (vi) necesidad de un amplio conocimiento técnico de los peritos y árbitros para resolver sobre daños ambientales derivados de actividades petroleras en zonas de difícil acceso; etc. Estas situaciones hacen necesario el análisis de las consideraciones de ambos Tribunales que justificaron sus decisiones.

Palabras Clave: Daño, Ambiental, Responsabilidad, Cuantificación, Contradicción.

\section{The Burlington and Perenco awards: An analysis of the environmental discrepancies in the quantification of damages and liability determination}

Aвstract: The counterclaims filed by Ecuador before the International Centre for Settlement of Investment Disputes (ICSID) for environmental damages in the oil operation of Blocks 7 and 21 of the Ecuadorian territory, resulted in atypical situations for arbitration practice: (i) the filing of two claims for the same environmental damages produced in the same geographical area; (ii) the claimant's express pretension that in the end, the most favorable decision would be chosen; (iii) the application of different rules to establish civil liabilities; (iv) the contrary assessment of the same expert reports by the two Tribunals; (v) the issuance of a subsequent arbitration award that "complemented" the previous award, with respect to the quantification of damages; (vi) the need for a very broad technical knowledge of the experts and arbitrators to decide on environmental damages derived from oil activities in areas of difficult access; among others. All these situations make necessary the legal analysis of the considerations of both Tribunals 
that justified their decisions, as well as the manner in which they were adopted.

Keywords: Damages, Environmental, Liability, Quantification, Contradiction.

\section{INTRODUCCIÓN}

En mayo de 2021, un comité ad hoc del CIADI rechazó el pedido de nulidad que la República de Ecuador presentó en contra del laudo dictado por un tribunal de ese centro el 27 de septiembre de 2019 en el caso Perenco Ecuador Limited c. República del Ecuador. En ese laudo se resolvió, entre otras cuestiones, una reconvención ambiental que Ecuador había presentado para obtener una indemnización por un daño ambiental producido por explotación petrolera, por el que también Ecuador había contrademandado a Burlington Resources Inc. en otro arbitraje CIADI que se sustanció paralelamente. Cabe destacar que, durante algunos años (2002 al 2009), Perenco y Burlington realizaron la explotación petrolera en esos bloques, mediante un consorcio, siendo aquella la única operadora.

Durante la sustanciación de los arbitrajes, Ecuador reconoció que ambos arbitrajes eran paralelos ${ }^{1}$; no refutó la acusación de pretender "idéntica compensación traslapada con respecto al mismo daño presunto en ambos procedimientos" ${ }^{2}$; y, explicó que su pretensión no era "recuperar dos veces la indemnización por daños reclamada, sino que invocará cualquier decisión que resulte ser más favorable a su posición" ${ }^{\prime 3}$, lo que activó el riesgo de una doble recuperación. Ante esto, el Tribunal de Burlington c. Ecuador preguntó a las partes si aceptarían que los tribunales de ambos casos realicen una coordinación entre ellos, para reducir el riesgo de decisiones contradictorias. Ecuador se negó rotundamente, por lo que, los tribunales estuvieron impedidos de efectuar la coordinación.

1. Burlington Resources Inc. c. República del Ecuador, ICSID Case No. ARB/08/5, Award, $7 / 2 / 2017$.

2. Ídem.

3. Ídem. 
Ecuador obtuvo dos decisiones favorables a su único interés de restaurar el ambiente en los bloques petroleros 7 y 21 de su territorio. En un primer laudo, un Tribunal CIADI ordenó que Burlington pague a Ecuador la suma de 39.1 millones de dólares americanos por ese concepto; y, en un laudo posterior, otro Tribunal CIADI ordenó que Perenco pague a Ecuador, adicionalmente, la suma de 54.4 millones de dólares americanos por ese mismo concepto. En total, Ecuador obtuvo dos laudos favorables por la suma de 93.6 millones de dólares americanos.

Hasta aquí, la primera interrogante que este artículo abordará es si es aceptable que la reclamante pretenda sustanciar paralelamente dos arbitrajes sobre lo mismo para elegir la resolución que más convenga a sus intereses, y que, siendo esto de conocimiento de los Tribunales, se haya decidido en derecho continuar con la sustanciación de los arbitrajes hasta su conclusión.

El presente artículo, además, centra su atención en cinco particularidades de esos procesos arbitrales, que hacen que sus respectivos laudos sometan a discusión su peculiar composición, así como la interrelación de uno con otro. La primera está relacionada con la materia de la controversia, ya que, al tratarse de la afectación de un ecosistema sensible de difícil acceso, por la realización de actividades consideradas como de alto riesgo (petroleras), era indispensable la opinión técnica de un perito en la materia, y el conocimiento técnico de los árbitros.

La segunda particularidad -quizás la más importante- guarda relación con la discrepancia en la aplicación de la regla para determinar la responsabilidad civil del causante del daño; para uno de los tribunales, la responsabilidad era "objetiva", mientras que, para el otro, la responsabilidad era "subjetiva" y dependía de si había existido un manejo diligente por parte de la petrolera.

La tercera, va relacionada a la prueba aportada por una de las partes; para uno de los tribunales, el peritaje de Ecuador fue determinante para cuantificar los daños que mandó a pagar en el laudo, mientras que, el otro, señaló que ese mismo peritaje y el de la contraparte no inspiraban "un suficiente grado de confianza sobre 
las condiciones reales de los Bloques", por lo que requirió un nuevo peritaje independiente ${ }^{4}$.

La cuarta -que guarda relación con la anterior- es que para uno de los tribunales hacer una visita in situ era vital, mientras que, para el otro, esa visita no lo era, dejando la suerte del caso en manos de un perito que sí debía visitar el sitio, pero con facultades limitadas impuestas por el mismo Tribunal.

Por último, la quinta particularidad llama la atención por la forma utilizada para la determinación del valor de la remediación ambiental, a través de la cual uno de los Tribunales hizo una inferencia para ampliar la cuantificación de los daños en virtud de sitios que su perito "pasó por alto o no pudo muestrear5.

Analizado lo anterior, surge la interrogante: ¿puede un laudo posterior modificar un laudo anterior en lo que respecta a la cuantificación del monto de una misma remediación ambiental? Esto fue lo que en efecto ocurrió.

\section{LA SOFISTICADA TECNICIDAD DE LAS RECLAMACIONES AMBIENTALES EN LOS ARBITRAJES EN DERECHO}

Dentro de todo tipo de reclamaciones, existe cierto grado de complejidad que, de manera general, suele ir atado a cuestiones relacionadas al fondo de lo que se disputa, o a la existencia de un convenio arbitral oscuro o diminuto, o a la determinación de asuntos formalistas del procedimiento. Estos problemas normalmente encuentran su solución en la sencilla aplicación de las normas jurídicas generales, sumadas a los criterios legales del Tribunal que las aplica, lo que resulta suficiente para suplir la complejidad que puede presentarse en el inicio y la sustanciación de un procedimiento arbitral.

Sin embargo, con la evolución del mundo, y el desarrollo de la inversión internacional, se ha sumado importancia a cuestiones

4. Perenco Ecuador Limited. c. República del Ecuador, ICSID Case No. ARB/08/6, Award, 27/9/2019.

5. Perenco Ecuador Limited. c. República del Ecuador, ICSID Case No. ARB/08/6, Award, 27/9/2019. 
técnicas de materias específicas, que por su naturaleza, se escapan de la esfera de la legalidad, y requieren un análisis específico y ajustado a su ciencia, al punto de que se vuelva imposible para un Tribunal -cuando el arbitraje es pactado en derecho- tomar una decisión sobre un asunto controvertido puesto a su conocimiento sin involucrar la participación de un especialista que le proporcione la información necesaria para llenar la falta de conocimiento técnico de ese Tribunal. Una de estas materias es la ambiental, que gana un grado más de complejidad cuando es necesario estudiar daños ocasionados en los denominados "ecosistemas sensibles", y que se vuelve aún más difícil cuando esos daños nacen como consecuencia de la ejecución de actividades de riesgo como lo es la actividad petrolera.

Esta afirmación reconocida por la doctrina obliga a los magistrados, además de tener la suficiente formación jurídica, a "buscar una formación interdisciplinaria o transdiciplinaria" Adicionalmente, para ser considerado como un abogado apropiado para tratar esta clase de litigios, se debe "abarcar el caso con la colaboración de otros profesionales de otras ciencias que le permitan tener una idea clara de los casos que se le presentan y de su resolución"7.

En este punto se puede observar la importancia de la participación de un experto, a quien se denomina perito, cuando se ha pactado que la solución de una controversia sea resuelta en un arbitraje en derecho, y que el centro de ella verse en temas netamente técnicos como es el ambiental.

\subsection{El carácter vinculante de los informes periciales}

Resulta poco probable creer que la larga disputa en los casos Burlington c. Ecuador y Perenco c. Ecuador -con lo que respecta a las reconvenciones- haya concluido con decisiones tomadas por un Tribunal con amplio entendimiento y experiencia en temas jurídicos y arbitrales, pero sin la experiencia técnico-ambiental, si no hubiese existido la importante participación de peritos ambientales que

6. C. A. Rodríguez. "El papel del juez ambiental en la protección del ambiente", en L. Pacheco Barassi (Coor), Summa Ambiental. Doctrina-Legislación-Jurisprudencia, Tomo II, Revista de Derecho Ambiental, 2011.

7. Ídem. 
aclaren la situación técnico-ambiental del daño reclamado por Ecuador.

Es importante en este punto analizar en qué grado los Tribunales estuvieron obligados a acoger el resultado de un peritaje para formarse un criterio que fue plasmado en su decisión final teniendo en consideración que esos arbitrajes -con lo que respecta a las reconvenciones- basaron su discusión en situaciones técnicas y no jurídicas.

Atendiendo la primera premisa, en principio, podría considerarse la total libertad y discrecionalidad del Tribunal para acoger o no un criterio pericial. El arbitraje se rige por un sistema abierto en cuanto a la introducción, admisión y valoración de pruebas, siempre encaminado al mejor esclarecimiento de los hechos para llegar a la verdad procesal y la emisión de decisiones más ajustadas a la realidad. Esta potestad discrecional, fue otorgada por las Reglas Procesales Aplicables a los Procedimientos de Arbitraje (Reglas de Arbitraje) del CIADI, aplicable en los casos sujetos a análisis, en las que, en su artículo 34 se dispone que

(1) El Tribunal decidirá sobre la admisibilidad de cualquiera prueba rendida y de su valor probatorio. (2) El Tribunal podrá, si lo estima necesario en cualquier etapa del procedimiento: (a) requerirle a las partes que presenten documentos, testigos $\mathrm{y}$ peritos; y (b) visitar cualquier lugar relacionado con la diferencia o llevar a cabo indagaciones en él. (3) Las partes cooperarán con el Tribunal en la producción de la prueba y en las demás medidas contempladas en el párrafo (2). El Tribunal tomará nota formal del incumplimiento por una parte de sus obligaciones de acuerdo con este párrafo y de las razones aducidas para tal incumplimiento. (4) Se considerará que los gastos incurridos en la presentación de la prueba y la adopción de las demás medidas previstas en el párrafo (2) son parte de los gastos incurridos por las partes, como lo dispone el Artículo 61(2) del Convenio ${ }^{8}$.

Sin ser muy específica, esta disposición le da entera libertad al Tribunal de decidir sobre las reglas del juego del proceso que le ha sido encomendado. Las disposiciones que le siguen a la disposición

8. Reglas Procesales Aplicables a los Procedimientos de Arbitraje del Centro Internacional de Arreglo de Diferencias relativas a Inversiones, (2006). Regla 34. 
legal antes expuesta, manejan la misma tendencia permitiendo al Tribunal decidir sobre admitir o no la prueba proporcionada por las partes, disponer la interrogación de testigos y peritos de una forma diferente, visitar, cuando lo crean pertinente los lugares relacionados con la controversia o llevar a cabo indagaciones de estos lugares, entre otras cosas, siempre encaminadas al esclarecimiento de los hechos a los ojos del Tribunal.

A pesar de lo antes dicho, la particularidad de las reconvenciones presentadas por Ecuador en contra de Burlington y Perenco, versan sobre asuntos de daño ambiental en territorios de la Amazonía ecuatoriana por la operación de actividades petroleras. Este es un tema en el que se necesita un amplio conocimiento técnico ambiental que los árbitros normalmente no poseen. Resulta entonces válido plantearse la siguiente pregunta: ¿Cómo podría un Tribunal resolver en derecho una controversia que versa sobre aspectos netamente técnicos sin el apoyo de un especialista en la materia? Para la doctrina, en aspectos de naturaleza técnica, la participación de un perito es imprescindible y "puede llegar a convertirse en una pieza clave para la decisión que tendrá que tomar el tribunal" ${ }^{\prime}$. La participación de los peritos tiene dos finalidades: "aclararle al tribunal arbitral las cuestiones de hecho, y opina también interpretando, desde su perspectiva técnica, los hechos del caso" ${ }^{\prime 10}$.

No obstante la inexistencia de una regulación de carácter legal que imponga la participación de un perito en arbitrajes pactados en derecho, con una discusión asentada en circunstancias técnicas, la realidad es que termina convirtiéndose en una especie de obligación natural que nace de la necesidad del Tribunal de conocer bien los hechos de la controversia para poder resolverla, y la consustancial inexperiencia del Tribunal en aspectos técnicos.

En el caso Burlington c. Ecuador, sin perjuicio que el Tribunal visitó el lugar en donde se produjo el daño, se acompañó a su razonamiento, la opinión de dos peritos presentados por las partes (GSI y IEMS), que coadyuvaron a llegar a la decisión que se plasmó en el laudo. En el caso Perenco c. Ecuador, además de la opinión de estos dos peritos (los del caso Burlington c. Ecuador), el Tribunal

9. H. Ezcurra. "Cuando los abogados sobran. Peritos”, en A. Bullard Gonzáles (Ed.), en Litigio Arbitral. El arbitraje desde otra perspectiva, Primera Edición, Palestra, 2016.

10. Ídem. 
consideró necesaria la participación de un tercer experto cuyo criterio fue acogido sobre los anteriores, y utilizado por el Tribunal para llegar a la decisión que se plasmó en el laudo.

\subsection{Prevalencia del laudo posterior y sus consideraciones técnicas sobre un laudo anterior}

En razón de haberse sustanciado paralelamente las dos reconvenciones propuestas por Ecuador por la misma afectación ambiental en los bloques 7 y 21 en contra de Burlington y Perenco, por Tribunales diferentes, quienes, por decisión de Ecuador no pudieron actuar en coordinación, ocasionó que se practicaran, entre otras pruebas, peritajes que llegaron a conclusiones diferentes respecto del área afectada, el grado de afectación, las medidas de remediación, y la forma de calcular el monto necesario para esa remediación.

Los distintos resultados le impusieron a los Tribunales la necesidad de hacer una evaluación de cuál de los informes debía prevalecer y por qué. El problema de este análisis impuesto tácitamente en el desarrollo de los arbitrajes a los Tribunales, es que las evaluaciones dadas en los peritajes no tienen naturaleza legal sino eminentemente técnica que, por ser distintas, podrían ocasionar que ninguno de ellos sea vinculante pese a la necesidad de tomar en consideración dicho criterio técnico.

Si la disputa sobre la cual ocurriese esta eventualidad fuera solucionable tomando únicamente como referencia las disposiciones legales y los principios jurídicos aplicables en la materia, el resultado común sería que exista una igualdad de criterios y como consecuencia de decisiones, dejando a salvo la posibilidad de que ocurra lo contrario por interpretaciones distintas de la ley.

Sin embargo, siendo un conflicto de asuntos ambientales, y, siendo indispensable entrar a valorar la opinión de un tercero, quien, en base a su conocimiento, pone en consideración del Tribunal, conclusiones basadas en aspectos técnico ambientales, que si bien son de gran ayuda pero que el Tribunal no está en la obligación de acoger, el razonamiento final en los dos Arbitrajes puede no estar consensuado, lo que crea nuevas interrogantes jurídicas en 
la aplicación del Arbitraje en Derecho sobre asuntos de carácter ambiental.

Es interesante analizar en qué se basó el Tribunal que manejó el caso Burlington c. Ecuador, para llegar a la imposición de responsabilidad por afectación al ambiente, así como cuál es el razonamiento del Tribunal que manejó el arbitraje Perenco c. Ecuador para descartar dos arbitrajes previamente evaluados por el Tribunal de Burlington c. Ecuador, así como la determinación del daño que este Tribunal ya había realizado y nombrar un perito independiente aceptando su opinión para tomar la decisión y expedir el laudo.

El Tribunal a cargo del arbitraje Burlington c. Ecuador, luego de analizados los peritajes presentados por las partes (de GSI y IEMS), y escuchadas las intervenciones en la Audiencia, llegó a la conclusión de que resultaba necesaria la visita a los sitios en donde se ocasionó la afectación a la naturaleza, para mejor entendimiento de los hechos, basándose en la potestad de hacerlo que se contempla en la regla 34 numeral (2), literal (b) de las Reglas Procesales Aplicables a los Procedimientos de Arbitraje, y sugirió a las Partes lo siguiente:

una inspección de diversos sitios sería de ayuda para su entendimiento de varios temas fundamentales relacionados con las reconvenciones ambientales, tales como la contaminación del suelo y de las aguas subterráneas, los programas de muestreo de los peritos, el uso del suelo, la topografía de los Bloques y de ciertos sitios, y el extenso modelado y delineación empleada por los respectivos peritos de las Partes ${ }^{11}$.

Además, a raíz de no haber sido solicitado por las partes, el Tribunal consideró innecesaria la participación de un perito independiente.

De lo antes dicho, se puede colegir que este Tribunal, consideró como indispensable, más que la opinión de un experto independiente a las partes (teniendo en cuenta que ya existían dos peritajes dentro del proceso), la visita al lugar de los hechos para un

11. Burlington Resources Inc. c. República del Ecuador, ICSID Case No. ARB/08/5, Award, $7 / 2 / 2017$. 
mejor entendimiento del tema, que le permita emitir una decisión basada en su discreción.

Por otro lado, el Tribunal a cargo del arbitraje Perenco c. Ecuador, después de tener acceso a los peritajes presentados por las partes en el caso Burlington c. Ecuador, expidió un laudo provisional y llegó a la conclusión de que entre los peritajes existían muchas diferencias, y que cada uno intentó obtener el mejor resultado con relación a la parte que lo solicitó por lo que no eran criterios objetivos. En la mencionada resolución provisional, el Tribunal expuso lo siguiente:

El Tribunal considera que cada uno estaba intentando obtener el mejor resultado para la parte que los instruyó, y que cruzaron los límites entre el análisis objetivo profesional y la reparación de las Partes. Es evidente para el Tribunal que los peritos estaban efectivamente apuntando a diferentes objetivos y esto ha dificultado mucho el trabajo de este Tribunal. ${ }^{12}$

Frente a esta insuficiencia técnica, el Tribunal fue consciente de que, para poder arribar a una decisión justa, necesitaba el esclarecimiento de los hechos técnico-ambientales.

El Tribunal razona que estos espacios vacíos deben llenarse y que los conflictos técnicos deben resolverse para poder llegar a una resolución adecuada y justa de la reconvención del Ecuador...el Tribunal no posee la experiencia técnica requerida para decidir entre los desacuerdos de peritos sobre asuntos de gran precisión técnica, se siente igualmente incómodo con la opción de simplemente elegir un grupo de conclusiones de peritos por encima del otro. ${ }^{13}$

Como solución a esta falta de información precisa, y con la intención de conseguir información técnico-ambiental de utilidad para la determinación del daño, así como de la correspondiente remediación, el Tribunal consideró que era indispensable la comparecencia de un perito ambiental independiente, cuyos estudios técnicos sean direccionados por las instrucciones del mismo Tribunal, pero que le ayuden a entender desde la perspectiva

12. Perenco Ecuador Limited. c. República del Ecuador, ICSID Case No. ARB/08/6, Award, 27/9/2019.

13. Ídem. 
técnico ambiental la magnitud del daño y la forma de determinar su remediación.

En definitiva, la potestad de involucrar a un perito de oficio no nace de la imaginación del Tribunal, tiene su sustento en el artículo 6 de las Reglas Sobre la Tramitación Eficiente de los Procedimientos en el Arbitraje Internacional, que permiten al Tribunal "de oficio y una vez oídas las partes, podrá nombrar a uno o más peritos para que dictaminen sobre aquellos asuntos discutidos que requieran un conocimiento especial". ${ }^{14}$

En este punto, encontramos la primera gran discrepancia entre Tribunales. En ambos casos, los Tribunales conocieron los mismos informes periciales presentados por las partes, pero ambos coincidieron en que esto no era suficiente para poder formarse un juicio y expedir su decisión. Ambos, conscientes de la falta de información certera, se propusieron indagar más sobre el aspecto técnico. Por un lado, el Tribunal que conoció el caso Burlington c. Ecuador optó por realizar la visita del sitio; y, por otro lado, el Tribunal que conoció el caso Perenco c. Ecuador optó por nombrar un perito independiente que vaya al sitio y que emita un informe sobre las directrices que el mismo Tribunal le proporcionó. Ambos mecanismos se encuentran permitidos por las reglas que regulan el Arbitraje Internacional, así que no existe ningún problema en escoger un método $\mathrm{u}$ otro.

Si estos arbitrajes no tuvieran ningún tipo de relación, la decisión tomada por dos Tribunales independientes, en arbitrajes independientes, sobre cual método para esclarecimiento de hechos es el más conveniente, no devendría en un conflicto arbitral; pero como los dos Arbitrajes sujetos a estudio recaen sobre una misma imputación, que, en concreto es sobre un mismo daño ambiental en la Amazonía ecuatoriana, esta situación, que es totalmente permitida, ha acaecido en la expedición de dos decisiones contradictorias dictadas por Tribunales del mismo centro, que tienen importantes distinciones relacionadas a la forma de determinar el daño y de cuantificar el daño lo que llevó a la modificación de un laudo con la expedición de un laudo posterior, aunque en otro caso.

14. Reglas sobre la Tramitación Eficiente de los Procedimientos en el Arbitraje Internacional, (Reglas de Praga) (2018). Regla 6. 


\subsubsection{Métodos investigativos para el esclarecimiento de los hechos}

En discusiones en donde el centro de la controversia se basa en temas ambientales, a las que debe darse más valor, a la decisión basada en la opinión de un experto que con su experiencia y conocimiento estudia el daño in situ y pone sus conclusiones a las órdenes del Tribunal, o la discreción del Tribunal que, luego de haber realizado una visita in situ con la finalidad de conocer los hechos, toma su decisión de acuerdo a su entendimiento y raciocinio.

En la reconvención contra Burlington, el Tribunal, luego de analizadas las pruebas presentadas por las partes y verificados los presupuestos expuestos mediante una visita al lugar de la controversia, tomó una decisión basada en su discreción. Por otro lado, en la reconvención contra Perenco, el Tribunal Arbitral luego de haber descartado los peritajes presentados por las partes al considerarlos como parcializados, basó su decisión en las conclusiones propuestas por el perito independiente (aceptado por las partes) señor Scott MacDonald, para la determinación del daño y calcular el costo de la remediación.

\subsubsection{Formas de cuantificar el daño ambiental}

En la cuantificación del daño, los Tribunales tampoco llegaron a un consenso.

Para el Tribunal del caso Burlington c. Ecuador, la determinación de la cuantificación se hizo de acuerdo a su buen juicio (a su discreción), y concluyó que "en las presentes circunstancias, es adecuado aplicar un costo unitario integral promedio de USD $300 / \mathrm{m} 3)^{15}$ " previamente habiendo concluido que "no encuentra justificaciones para no aplicar los precios locales"16

Por otro lado, el Tribunal del caso Perenco c. Ecuador, se basó en las estimaciones de costos que proporcionó el señor MacDonald,

\footnotetext{
15. Burlington Resources Inc. c. República del Ecuador, ICSID Case No. ARB/08/5, Award, $7 / 2 / 2017$.

16. Ídem.
} 
quien propuso que "los costos de la remediación se definieron a partir de una combinación de:

(i) presupuestos realizados por contratistas de remediación de Ecuador; (ii) presupuestos realizados por proveedores de materiales de Estados Unidos (es decir reactivos con experiencia en Ecuador; (iii) tasas de unidad verificadas previamente que fueron obtenidas por las Partes; y (iv) costos de unidad de remediación publicados en los Estados Unidos ${ }^{17}$.

Este punto es de crucial importancia por cuanto, en los dos laudos, se llegó a un costo de remediación considerablemente distinto. Para el laudo del caso Perenco c. Ecuador, aumentó el costo de remediación en un 58.13\%, imponiendo una remediación por USD 93.638.890,00. Para el Tribunal del caso Burlington c. Ecuador, el costo de la remediación se limitaba a la suma de USD 39.199.370.

El significativo incremento, evidentemente está relacionado con la forma de determinar el costo, que fue totalmente distinto para los dos Tribunales, empezando por los lineamientos para determinarlo, en donde uno de los Tribunales decidió hacerlo a precios de Ecuador y el otro a precios internacionales, hasta en el método para determinarlo, ya que para uno de los Tribunales se aplicó el método subjetivo dejando en parte a la discrecionalidad del Tribunal, mientras que en el otro, de manera objetiva se determinó en base a cotizaciones de los contratistas de remediación.

Estas dos discrepancias entre los criterios de los Tribunales derivaron de cierta manera en que el Laudo del caso Perenco $c$. Ecuador, reformara o modificara el laudo del caso Burlington c. Ecuador, imponiéndole a Perenco el pago de un costo de remediación ambiental en lo que excediera del monto que fue ordenado a pagar en beneficio de Ecuador por el Tribunal del caso Burlington $c$. Ecuador, por ese mismo concepto.

Es decir, el segundo laudo tuvo una determinante incidencia frente al primero, en cuanto al monto de la remediación y a la determinación de responsabilidad, ya que, so pretexto de haber sido

17. Perenco Ecuador Limited. c. República del Ecuador, ICSID Case No. ARB/08/6, Award, 27/9/2019. 
expedido después, prevaleció el monto ordenado en este segundo laudo. Además, considerando la restauración "como la principal medida de responsabilidad ambiental"18, el segundo laudo de cierto modo asignó porcentajes de responsabilidad a los dos miembros del consorcio, asignándole el $58.13 \%$ de responsabilidad a Perenco y el $41.86 \%$ a Burlington, quien ni siquiera formó parte de este arbitraje.

Pese a que los Tribunales no actuaron en coordinación, se puede colegir que de cierto modo las actuaciones de un arbitraje sumaron en el otro, y que, el Tribunal encargado del caso Perenco c. Ecuador, en lo que le era provechoso, utilizó información del otro arbitraje, sobre todo para atribuir la existencia de la afectación ambiental, y la complementó o la modificó de acuerdo con su criterio basado en el informe del perito independiente. Esta forma de proceder es conocida como Heurística Anclaje-Ajuste, que consiste en la "tendencia humana de establecer un punto de referencia y realizar comparaciones a partir de este para poder estimar un valor"19.

Para tomar la decisión respecto del monto de la remediación ambiental, el Tribunal encargado del caso Perenco c. Ecuador, también aplicó este método Anclaje-Ajuste, tomando como punto de referencia las conclusiones del perito independiente. El problema de la aplicación de este método, es que, a criterio de la doctrina, "es un mecanismo de simplificación de toma de decisiones que puede llevar a un sesgo de confianza excesiva en el valor inicial cuando este es asignado arbitrariamente" ${ }^{20}$. En el caso Perenco c. Ecuador, no se asignaron presupuestos de manera arbitraria, sin embargo, tener como base las conclusiones del peritaje, le propinó la confianza suficiente al Tribunal como para resolver no hacer una visita de corroboración.

Lo interesante aquí radica en tratar de determinar por qué un laudo puede tener incidencia sobre otro, y por qué prevalece el segundo solo por el hecho de haberse expedido después. Por qué el método para el esclarecimiento de los hechos utilizado por el

18. S. Cavanillas Mugica. "Responsabilidad Civil y Riesgo". E. Pérez Alonso, E. Arana García, P. Mercado Pacheco, J. Serrano Moreno (Eds.), en Derecho, Globalización, Riesgo y Medio Ambiente, Tirant lo Blanch, 2012.

19. J. De LA JARA. "Condenados por intuición: el cerebro del juez en la determinación del daño y del factor de atribución", en A. Bullard GonZÁlez (Ed.), en Litigio Arbitral. El arbitraje desde otra perspectiva, Primera Edición, Palestra, 2016.

20. Ídem. 
Tribunal del caso Perenco c. Ecuador es más óptimo para este tipo de controversias que el utilizado por el Tribunal del caso Burlington c. Ecuador. Por qué la forma de determinar el costo de remediación utilizado por el Tribunal del caso Perenco c. Ecuador es más exacto que el utilizado por el Tribunal del caso Burlington c. Ecuador.

Viendo las cosas de la forma sencilla, el Tribunal del caso Burlington c. Ecuador llegó a sus conclusiones sin ser expertos en la materia, haciéndose su propio juicio luego de haber verificado lo alegado por las partes en una visita in situ y utilizando la sana crítica, mientras que el Tribunal del caso Perenco c. Ecuador llegó a sus conclusiones a través de la opinión de un experto que visitó el sitio, dándole a este tercero "un voto de fe", pero sin haber sido el propio Tribunal quien verifique los hechos alegados por las partes a través de una visita. Sin embargo, el laudo que prevaleció fue el de este segundo Tribunal.

\subsection{VISITA IN SITU DEL TRIBUNAL VS PERITAJE}

En este tipo de arbitrajes es común que las partes no aporten con la información suficiente para que los árbitros armen su juicio de valor y estén en capacidad de expedir un laudo; o que, a pesar de haber sido aportada la información, esta sea imprecisa, o genere una serie de interrogantes para los profesionales en derecho que tienen en su poder la decisión sobre el conflicto puesto en su conocimiento.

Como es natural, cada una de las partes aportará la prueba que mejor vele a sus intereses, la cual no siempre sirve para conocer la realidad objetiva del problema, sino que se limita a mostrar la posición de cada una de las partes y esto no siempre es provechoso para el Tribunal.

Ocurre también -como en efecto sucedió en los casos analizadosque se acompañan al proceso peritajes "imparciales", que a juicio del Tribunal luego de su constatación no son convenientes para llegar a una determinación objetiva.

Para estas circunstancias, las reglas que regulan el arbitraje internacional, proponen alternativas que el Tribunal de oficio puede aplicar para llegar a un conocimiento más real de los hechos en 
disputa. Lo permiten las Reglas IBA (International Bar Association) sobre Práctica de Prueba en el Arbitraje Internacional (artículo 7 numeral 6 y 7) 21; las Reglas sobre el Tratamiento Eficiente en el Arbitraje Internacional (Reglas de Praga) (artículo 6 numerales 6.1 y 6.5)22 y las Reglas Procesales Aplicables a los Procedimientos de Arbitraje del CIADI (Reglas de Arbitraje) (artículo 34 numeral (2) literal (b) 37 numeral (1) ${ }^{23}$.

Entre las principales alternativas, encontramos que el Tribunal puede por su propia iniciativa, visitar el sitio para corroborar los hechos expuestos por las partes, $y$, formarse un criterio para en él basar su decisión como lo hizo el Tribunal del caso Burlington c. Ecuador. Otra alternativa interesante es la selección de un perito independiente para que lleve a cabo indagaciones en el lugar de la controversia y presente ante el Tribunal sus conclusiones como ocurrió en el caso Perenco c. Ecuador.

21. Reglas de la IBA (International Bar Association) sobre Práctica de Prueba en el Arbitraje Internacional, (2010).

Artículo 6. Peritos Designados por el Tribunal Arbitral, 7. Cualquier Dictamen Pericial emitido por un Perito Designado por el Tribunal Arbitral y sus conclusiones serán valorados por el Tribunal Arbitral con la debida consideración de todas las circunstancias del caso.

Artículo 7 Inspección Sujeto a las disposiciones del Artículo 9.2, el Tribunal Arbitral podrá, a instancia de una Parte o por iniciativa propia, inspeccionar o solicitar la inspección por un Perito Designado por el Tribunal Arbitral o un Perito Designado por las Partes de cualquier lugar, propiedad, maquinaria o cualesquiera otros bienes, muestras, sistemas, procesos o Documentos que considere apropiados. El Tribunal Arbitral deberá, previa consulta a las Partes, determinar el momento y las circunstancias de la inspección. Las Partes y sus representantes tendrán derecho a estar presentes en cualquiera de estas inspecciones.

22. Reglas sobre la Tramitación Eficiente de los Procedimientos en el Arbitraje Internacional, (Reglas de Praga) (2018).

Artículo 6. Peritos. 6.1. El tribunal arbitral, a solicitud de una parte o de oficio y una vez oídas las Partes, podrá nombrar a uno o más peritos para que dictaminen sobre aquellos asuntos discutidos que requieran un conocimiento especial.

6.5. El nombramiento de cualquier perito por el tribunal arbitral no impide que una parte aporte su propio dictamen pericial. Este perito nombrado por la parte estará disponible para la ratificación de su informe durante la audiencia, a instancia de la otra parte o, de oficio, por el tribunal arbitral.

23. Reglas Procesales Aplicables a los Procedimientos de Arbitraje del Centro Internacional de Arreglo de Diferencias relativas a Inversiones, (1966).

Regla 34 Prueba: principios generales 2) El Tribunal podrá, si lo estima necesario en cualquier etapa del procedimiento: (b) visitar cualquier lugar relacionado con la diferencia o llevar a cabo indagaciones en él.

Regla 37 Visitas e investigaciones; presentaciones de partes no contendientes (1) Si el Tribunal considerase necesario visitar cualquier lugar relacionado con la diferencia o llevar a cabo indagaciones en ese lugar, dictará una resolución al efecto. La resolución definirá el alcance de la visita o el objeto de las indagaciones, el plazo, el procedimiento que se deberá seguir y los demás detalles. Las partes podrán participar en toda visita o indagaciones. 
En un lado de la moneda tenemos el Tribunal que, con sus propios ojos presenció la situación materia de su arbitraje y, por el otro lado, tenemos al Tribunal que, consciente de la tecnicidad del asunto, derivó el estudio a un tercero experto en la materia.

Para arbitrajes relacionados con temas técnicos ambientales, es importante abrir debate respecto de qué alternativa resulta más útil o apropiada, ya que, en la primera de ellas, el Tribunal presencia pero, no siempre conoce todos los temas técnicos necesarios para abordar un estudio de esa magnitud, mientras que el problema de la segunda opción es que, quien tiene el poder de decisión nunca verifica lo expuesto por el perito, nunca lo conoce a ciencia cierta, sino que da un voto de fe.

Estas alternativas no tienen por qué ser excluyentes. Bien podría coexistir la visita del Tribunal al sitio de la controversia y la participación de un perito independiente que realice su estudio en base a su conocimiento y experiencia y que le brinde información al Tribunal no solo en papeles, sino también en información de carácter práctico al momento de realizar la inspección.

La combinación de estos dos medios probatorios, permitirían al Tribunal que es quien tiene el poder de decisión sobre la causa, usar su discreción para tomar una decisión basándose en lo observado, en combinación con el conocimiento brindado por el perito independiente.

\section{COMPETENCIA DE LOS TRIBUNALES PARA DETERMINAR RESPONSABILIDADES A LAS PARTES Y A TERCEROS}

\subsection{Responsabilidad subjetiva vs. responsabilidad objetiva}

No está en discusión que distintos Tribunales, aunque pertenezcan a un mismo centro de arbitraje, puedan hacer consideraciones distintas, o llegar a conclusiones diferentes. Sin embargo, es interesante que dos Tribunales hayan utilizado diferentes fuentes del derecho de un determinado país para discrepar sobre la aplicación del sistema de responsabilidad civil extracontractual (subjetiva $u$ objetiva) de dos agentes que han 
cometido el mismo cuasidelito, contra la misma persona, dentro del mismo período y dentro de la misma zona geográfica.

Las consecuencias de esa discrepancia se agudizan cuando nos detenemos a analizar la amplitud o estrechez de los argumentos que pueden esgrimir las partes cuando se trata de ejercer sus respectivos derechos de defensa. El tema cobra aún más importancia cuando se considera que los causantes del daño eran socios y que solo uno de ellos era el operador de la actividad que causó el daño.

En lo que atañe a la responsabilidad civil extracontractual, el Código Civil de Ecuador consagró desde 1860, como regla general, que la persona que ha inferido daño a otra, a través de un delito o cuasidelito, está obligada a la indemnización ${ }^{24}$, incluso si es que el daño puede ser imputado a malicia o negligencia ${ }^{25}$ del causante ${ }^{26}$. Si son varias personas las causantes del daño, todas ellas serán solidariamente responsables ${ }^{27}$. Esta es la responsabilidad civil extracontractual subjetiva que se aplicó en Ecuador incluso para temas ambientales.

Una afirmación que goza de certeza es que, desde hace algunos años, la responsabilidad por temas ambientales es objetiva. Los Tribunales CIADI de Perenco y Burlington discrepan sobre el año en

24. Código Civil, Artículo 2214, RO Sup. No. 46, 24/06/2005.

Art. 2214.- El que ha causado un delito o cuasidelito que ha inferido daño a otro, está obligado a la indemnización; sin perjuicio de la pena que le impongan las leyes por el delito o cuasidelito.

25. Resulta importante destacar que la obligación de reparar el daño requiere al menos de la negligencia de la persona que lo causa. Por cultura general, la negligencia es sinónimo de la falta de cuidado. En nuestra legislación civil, desde siempre, la falta de diligencia y cuidado significa culpa.

26. Ídem. Art. 2229.

Art. 2229.- Por regla general todo daño que pueda imputarse a malicia o negligencia de otra persona debe ser reparado por esta. Están especialmente obligados a esta reparación: 1. El que provoca explosiones o combustión en forma imprudente; 2 . El que dispara imprudentemente una arma de fuego; 3 . El que remueve las losas de una acequia o cañería en calle o camino, sin las precauciones necesarias para que no caigan los que por allí transitan de día o de noche; 4. El que, obligado a la construcción o reparación de un acueducto o puente atraviesa un camino, lo tiene en estado de causar daño a los que transiten por él; y, 5. El que fabricare y pusiere en circulación productos, objetos o artefactos que, por defectos de elaboración o de construcción, causaren accidentes, responderá de los respectivos daños y perjuicios.

27. Ídem. Art. 2217.

Art. 2217.- Si un delito o cuasidelito ha sido cometido por dos o más personas, cada una de ellas será solidariamente responsable de todo perjuicio procedente del mismo delito o cuasidelito, salvo las excepciones de los Arts. 2223 y 2228. Todo fraude o dolo cometido por dos o más personas produce la acción solidaria del precedente inciso. 
el que empezó a aplicarse ese sistema. Lo cierto es que ese sistema se impuso como norma de rango constitucional en el año $2008^{28}$.

Este pequeño recuento histórico sobre el régimen legal aplicable a la responsabilidad civil extracontractual en materia de daños ambientales cobra importancia porque la explotación petrolera del consorcio conformado por Burlington y Perenco, se ejecutó años antes y años después de la expedición de la Constitución del 2008 (octubre) y su consecuente consagración de la responsabilidad objetiva.

Aunque parece difícil que ambos Tribunales llegasen a conclusiones distintas para asignar responsabilidades, en la práctica esto fue lo que ocurrió, verificándose así la segunda gran discrepancia entre ellos. El Tribunal de Perenco c. Ecuador determinó que la responsabilidad civil extracontractual subjetiva o basada en la culpa del agente, rigió las reclamaciones de Ecuador por daños ambientales anteriores a la Constitución de 2008. Por su parte, el Tribunal de Burlington c. Ecuador determinó que la responsabilidad civil extracontractual objetiva rigió las reclamaciones de Ecuador desde el año 2002, 6 años antes de la expedición de la Constitución actualmente vigente, basándose en la sentencia que dictó la Corte Suprema de Justicia (máxima Corte del Ecuador en ese entonces) en el caso Delfina Torres c. Petroecuador.

Conocido es que la existencia de dolo o culpa es indiferente cuando de determinar responsabilidad objetiva se trata. De hecho, la doctrina sostiene que "Si no es necesario ningún tipo de dolo o culpa, se denomina responsabilidad objetiva" ${ }^{29}$. Siendo esto así, entonces la principal consecuencia de arribar a conclusiones distintas está dada por el ejercicio del derecho a la defensa de las petroleras en sus respectivos arbitrajes. La responsabilidad civil extracontractual

28. Constitución de la República del Ecuador, Artículo 396, RO No. 449, 20/10/2008.

Art. 396.- El Estado adoptará las políticas y medidas oportunas que eviten los impactos ambientales negativos, cuando exista certidumbre del daño, el Estado adoptará medidas protectoras eficaces y oportunas. La responsabilidad por daños ambientales es objetiva. Todo daño al ambiente, además de las sanciones correspondientes, implicará también la obligación de restaurar integralmente los ecosistemas e indemnizará a las personas y comunidades afectadas. Cada uno de los actores de los procesos de producción, distribución, comercialización y uso de bienes o servicios asumirá la responsabilidad directa de prevenir cualquier impacto ambiental, de mitigar y reparar los daños que ha causado, y de mantener un sistema de control ambiental permanente. Las acciones legales para perseguir y sancionar por daños ambientales serán imprescriptibles.

29. O. Velásquez. Responsabilidad Civil Extracontractual, 2da. Ed., Temis, 2015. 
subjetiva permite al supuesto causante, ejercer un radio de acción defensivo mucho más amplio que el que se tiene en el mundo de la responsabilidad objetiva. Así, en aquella responsabilidad, el supuesto causante tiene la posibilidad de acreditar que actuó sin culpa, es decir haciendo uso del debido cuidado y diligencia en la explotación petrolera. En cambio, la responsabilidad objetiva determina la irrelevancia de la diligencia del causante del daño.

En efecto, el Tribunal de Burlington c. Ecuador arribó a la conclusión "de que en la legislación ecuatoriana la responsabilidad objetiva rigió las instancias de daño ambiental, a más tardar, desde que se dictó la decisión de Delfina Torres en el año 2002"30. De ese caso, el Tribunal señaló tres elementos característicos del régimen de responsabilidad objetiva por daño ambiental, siendo estos los siguientes: “(i) La parte actora debe probar el daño relacionado con las actividades de la demandada; (ii) no es necesaria la culpa; y, (iii) se presume causalidad, exonerándose a la demandada si prueba que el daño fue causado por fuerza mayor, por la víctima o por un tercero" ${ }^{31}$. También afirmó que "A plicado al presente caso, la ausencia de un requisito de culpa implica que Burlington no puede evitar la responsabilidad planteando que actuó de manera diligente" ${ }^{\prime \prime 2}$ y que “el operador solo podría escapar de la responsabilidad demostrando que el daño fue causado por un hecho fortuito, un tercero o la víctima" ${ }^{33}$, aunque aclaró que el primer requisito consiste en que el perjudicado -en el caso, Ecuador- prueba la existencia del daño y su relación con el causante. Para reforzar su aserto, ese Tribunal citó la sentencia de la Corte Suprema de Justicia en el caso Medardo Luna c. AECA, alegando que esa corte "sostuvo que resultaba irrelevante si la compañía cumplió con las regulaciones aplicables y si el piloto actuó con cuidado" ${ }^{34}$.

Por otro lado, el Tribunal de Perenco c. Ecuador concluyó que "para que las reclamaciones de Ecuador prosperen, el Tribunal debe estar convencido de que Perenco manifestó una falta de cuidado

30. Burlington Resources Inc. c. República del Ecuador, ICSID Case No. ARB/08/5, Award, $7 / 2 / 2017$.

31. Ídem.

32. Ídem.

33. Ídem.

34. Ídem. 
respecto de sus propios bienes o derechos" ${ }^{\prime 35}$. Previamente, el Tribunal consideró que:

recuerda que el Artículo 39 de los Artículos de la CDI, titulado "Contribución al perjuicio", establece que en la determinación de la reparación "se tendrá en cuenta la contribución al perjuicio resultante de la acción o la omisión, intencional o negligente, del Estado lesionado o de toda persona o entidad en relación con la cual se exija la reparación. Si bien la inclusión de la palabra "intencional" amplía el alcance del artículo más allá de la negligencia, dicha ampliación, en opinión del Tribunal, no pareciera ser sustancial. Los comentarios de la CDI señalaron a este respecto que el enfoque "[s]e refiere a las situaciones llamadas en los ordenamientos jurídicos nacionales "culpa concurrente", "comparative fault", "faute de la victime", etc. El comentario (5) al Artículo señala, además, que "solamente permite que se tengan en cuenta las acciones $\mathrm{u}$ omisiones que puedan considerarse intencionales o negligentes, es decir, cuando es manifiesto que la víctima de la infracción no ha ejercido la debida diligencia en relación con sus bienes o derechos" ${ }^{\prime \prime 6}$.

Además, es muy importante recordar que, en una Decisión Provisional, el Tribunal concluyó que:

"si ocurrió un exceso regulatorio, debe considerarse que Perenco incumplió con el deber requerido de cuidado y será responsable a menos que pueda demostrar sobre una preponderancia de la prueba: (i) la ocurrencia de un acontecimiento de force majeure; (ii) que no incumplió con el deber de cuidado respecto de esa instancia específica de contaminación; o (iii) que alguna otra persona causó el daño"${ }^{\prime 37}$.

Como se puede apreciar, la diferencia conceptual en las posibilidades de defensa de las petroleras radica en la posibilidad de sostener que actuaron con el deber de cuidado, y probarlo. A Perenco sí le fue permitido hacerlo, en cambio a Burlington no, a

35. Perenco Ecuador Limited. c. República del Ecuador, ICSID Case No. ARB/08/6, Award, 27/9/2019.

36. Ídem.

37. Ídem. 
pesar de que ambos casos se sustanciaron por los mismos hechos y reclamaciones, y ante el mismo centro de arbitraje.

Llama la atención que el Tribunal que emitió el primer laudo (caso Burlington c. Ecuador) era consciente de la posición del otro Tribunal (caso Perenco c. Ecuador), con respecto a la aplicación de la fuente del derecho para determinar la responsabilidad civil subjetiva para los daños ocurridos con anterioridad al 2008, y a pesar de eso decidió inclinarse por la corriente de la responsabilidad objetiva desde el año 2002.

Esto último es muy importante si se considera que Perenco se convirtió en parte de los contratos de participación (Bloques 7 y 21) en septiembre de 2002 -mismo año en el que se dictó la sentencia en el caso Delfina Torres c. Petroecuador que aplicó la responsabilidad civil extracontractual objetiva para actividades de alto riesgo- y si su caso hubiese sido conocido por el otro Tribunal (caso Burlington c. Ecuador), no hubiese tenido la más mínima oportunidad de sostener y probar que actuó con el deber de cuidado, siendo muy probable que le hubiese sido impuesto el pago del total del monto de la indemnización por remediación y no solo una parte de este que fue compartido con sus predecesoras y sucesora en la explotación petrolera. La otra cara de la moneda nos invita a imaginar qué habría sido de Burlington ante el otro Tribunal (caso Perenco c. Ecuador), es decir, si hubiese tenido la oportunidad de demostrar su diligencia al ejecutar la explotación petrolera, sobre todo si se considera que la diligencia se hubiese podido demostrar con el cumplimiento de los deberes formales de los titulares de obra que causan impacto al ambiente, los cuales en el pasado no eran tan rígidos como en estos días.

Siendo muy concretos, no solo merece ser puesto de relieve que, al final de cuentas, ambos Tribunales CIADI tomaron decisiones contradictorias sobre el año desde el cual Ecuador empezó a aplicar el régimen de la responsabilidad civil objetiva para daños ambientales (2002 c. 2008), sino que ambos Tribunales conocían plenamente las fuentes del derecho invocadas por las partes para inclinar la balanza a su favor en ese punto, y decidieron aplicar fuentes distintas (jurisprudencia c. Constitución). Incluso, el Tribunal que dictó el laudo posterior 
conocía que el otro Tribunal había tomado una decisión contradictoria a la suya.

Bien podría decirse que los Tribunales buscaron evitar la toma de decisiones contradictorias en ese y otros puntos, cuando uno de ellos solicitó a las partes procesales que se le permita trabajar en coordinación con el otro. No es menos cierto que, pese a lo contrarias que son las decisiones, en este caso triunfó la independencia de las decisiones de cada uno de los árbitros y, por ende, de cada uno de los Tribunales.

\subsection{Responsabilidad de terceros declarada en arbitrajes en los que no formaron parte}

Los Tribunales de los casos Burlington c. Ecuador y Perenco c. Ecuador analizaron la responsabilidad de las petroleras por la contaminación encontrada en varios sitios del territorio ecuatoriano.

En el caso Burlingtonc. Ecuador que determinóla responsabilidad objetiva de Burlington en lo referente a daños ambientales, el Tribunal hizo una ilación de ideas que empezó con la necesidad de que Ecuador demuestre la existencia del daño ambiental y que Burlington ejercía actividades de alto riesgo en las zonas contaminadas, para luego pasar a aplicar la responsabilidad objetiva y permitir a Burlington que se exima de responsabilidad alegando y probando que ocurrió un caso fortuito, o que el daño fue culpa de Ecuador, o de un tercero.

En todo caso, el Tribunal aclaró que "En otras palabras, bajo el régimen de responsabilidad objetiva, no se le puede atribuir responsabilidad a Burlington por daños que pueda probar hayan sido ocasionados por operadores anteriores" 38 , lo que se traduce que si Burlington no lograba probar la culpa de otros operadores (anteriores o posterior) sería declarada culpable de toda contaminación que se encuentre en las zonas contaminadas.

38. Burlington Resources Inc. c. República del Ecuador, ICSID Case No. ARB/08/5, Award, $7 / 2 / 2017$. 
Por su parte, el laudo del caso Perenco c. Ecuador es más específico. En este, el Tribunal determinó montos de remediación atribuibles a predecesoras de Perenco y sucesora de Perenco. Es así que, las predecesoras a Perenco y su sucesora -que no formaron parte del arbitraje- deberían, a criterio del Tribunal, pagar montos definidos por remediaciones a las piscinas de lodo y pozos instalados por Perenco; por remediaciones de suelo; y, por aguas subterráneas.

\section{LA POSIBILIDAD DE INICIAR DOS RECLAMACIONES PARALELAS SOBRE LO MISMO PARA ESCOGER LA RESOLUCIÓN QUE MÁS CONVENGA AL RECLAMANTE}

El perjudicado por un daño de naturaleza extracontractual, causado por varios agentes, tiene el derecho de iniciar una acción en contra de ellos. Nada le prohíbe iniciar varias acciones por separado. Tiene el derecho de accionar, derecho que está limitado por la figura del abuso del derecho. Presentadas las acciones, nada lo obliga a acumular los procesos.

Lo mismo aplica para el caso de varios daños cometidos de manera simultánea, por distintos agentes, en el mismo lugar, y en contra del mismo perjudicado. De igual forma, el perjudicado puede iniciar acciones separadas en contra de agentes que causaron daños en el mismo lugar, de forma consecutiva; o, cuando los daños fueron causados por agentes a los que los une una asociación o un consorcio.

Sin embargo, el inicio de acciones separadas en esos casos supone el riesgo de que se dicten decisiones contradictorias. El riesgo más evidente es que el demandante salga victorioso en uno de los casos, y derrotado en el otro, porque sería probable que se reconozca su derecho a ser indemnizado en un laudo, mientras que el otro laudo desconozca ese derecho. Otro de los riesgos sería que se dicten dos o más indemnizaciones por un mismo daño, pues esto se traduciría en una doble recuperación.

Las decisiones contradictorias pueden deberse a consideraciones distintas (hechos analizados en un caso y no en el otro), interpretaciones distintas (un Tribunal puede interpretar de 
forma distinta el derecho, con respecto a otro Tribunal), una defensa técnica diferente o, en otros casos, deficiente, etc. En todo caso, los Tribunales tienen la potestad de minimizar ese riesgo haciendo una coordinación entre ellos, o accediendo a la acumulación de los casos. En el arbitraje se necesita el consentimiento de las partes para que proceda la acumulación de procesos, o para permitir a los Tribunales que hagan coordinaciones entre ellos.

Los casos Burlington c. Ecuador y Perenco c. Ecuador analizan los mismos hechos (contaminación en una misma área geográfica); recogen pretensiones iguales (indemnización por la misma suma de dinero); someten a análisis básicamente las mismas pruebas de las partes (peritajes de IEMS y GSI); estudian la responsabilidad de petroleras que estaban consorciadas, aunque solo una de ellas operaba la actividad de explotación de petróleo; etc. Esto fue reconocido abiertamente por Ecuador en los arbitrajes, y aceptado por ambos Tribunales que incluso conocieron la explicación de Ecuador "que no pretende recuperar dos veces la indemnización por daños reclamada, sino que invocará cualquier decisión que resulte ser más favorable a su posición" ${ }^{\prime 39}$.

En la práctica, Ecuador presentó dos demandas que no fueron fruto de su proactividad, sino que más bien podrían considerarse reactivas ante sendas demandas que habían sido presentadas, por separado y ante el mismo centro internacional de arbitraje, por las compañías que conformaron el consorcio que estaba a cargo de la explotación petrolera en unárea geográfica ecuatoriana determinada. Es por ello, que esas contrademandas o reconvenciones fueron presentadas dentro del marco del ejercicio del derecho a la defensa que, concretamente, permitió a Ecuador no solo oponer excepciones a las demandas de Burlington y Perenco, sino además presentar reconvención, aunque con identidad de hechos y pretensiones. En todo caso, independientemente de lo que haya ocurrido, fueron Burlington y Perenco las que iniciaron estos procesos arbitrales por separado y con un intervalo muy corto. Haciendo un parangón de lo ocurrido, Burlington y Perenco eligieron las canciones, y a Ecuador solo le tocó bailar apegado a esos ritmos. Sin embargo, eso no deja la sensación derivada del ejercicio correcto del derecho de acción.

39. Burlington Resources Inc. c. República del Ecuador, ICSID Case No. ARB/08/5, Award, $7 / 2 / 2017$. 
En la legislación del Ecuador existe la figura del Abuso del Derecho y se dice que ocurre "cuando su titular excede irrazonablemente y de modo manifiesto sus límites, de tal suerte que se perviertan o se desvíen, deliberada y voluntariamente, los fines del ordenamiento jurídico" ${ }^{40}$. Entre los fines del Derecho y, concretamente del Derecho Procesal, no se encuentra que el demandante tenga una doble oportunidad de someter los mismos hechos y pretensiones a consideración de jueces distintos, o que tenga una doble oportunidad de victoria.

En el ámbito del arbitraje internacional, los centros deben endurecer sus reglamentos para impedir que este tipo de prácticas de abuso del derecho se cometan.

\section{Conclusiones}

Dentro del mundo de las controversias sometidas a resolución en arbitraje en derecho, las reclamaciones ambientales tienen su particularidad, básicamente por su complejidad técnica que demanda de los abogados (árbitros) una preparación adicional. Esta preparación es necesaria tanto para analizar el caso, esclarecer los hechos, formarse un juicio, emitir un laudo, pero sobre todo para trabajar en conjunto con un tercero experto en la ciencia de daños ambientales. Al final de cuentas, los árbitros resuelven la controversia según su discreción -como ocurrió en Burlington c. Ecuador- o en base a las conclusiones de ese experto -como ocurrió en Perenco c. Ecuador. En todo caso, la visita del sitio por parte de los árbitros no es una mera ritualidad sino un acto indispensable para esclarecer los hechos que le expusieron las partes, así como para corroborar las conclusiones del experto.

Por otro lado, la finalidad del derecho internacional es la uniformidad de criterios. En materia de responsabilidad civil extracontractual por daños al ambiente, esto se torna complejo cuando existen dos sistemas para aplicar responsabilidades para distintos causantes, en el mismo asunto, y durante el mismo período. Si la aplicación por parte de los Tribunales es distinta,

40. Código Civil. Artículo sin número anterior al Artículo 37, RO Sup. No. 46, 24/06/2005. 
lo más seguro es que se generen distorsiones en lo relacionado al ejercicio del derecho a la defensa de los causantes del daño.

Asimismo, si bien es cierto que el derecho a demandar y, sobre todo, el de contrademandar, no puede verse limitado, es muy necesario que los centros de arbitraje reglamenten sobre los casos en los que esa facultad de accionar constituya un abuso del derecho, y lo impidan. Al momento, esto no está reglado y, consecuentemente, no está prohibido.

Por último, la existencia de controversias interrelacionadas debería ser per se una llave para que los Tribunales que conozcan esas controversias se sientan en la posibilidad de trabajar coordinadamente para evitar decisiones contradictorias. 


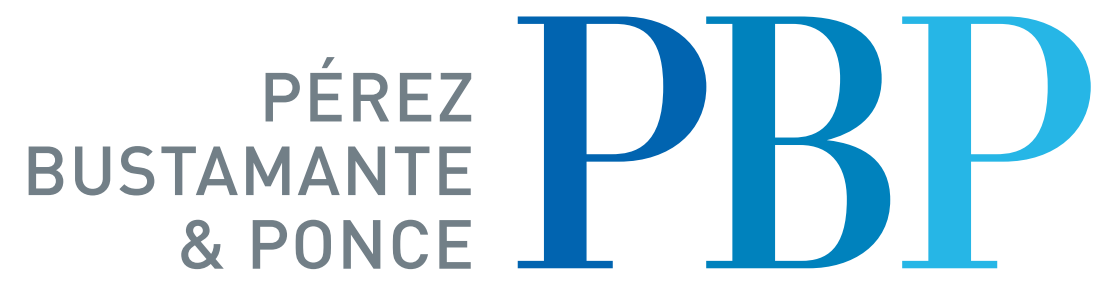

\section{Entendemos los negocios, pensamos en el país, ideamos soluciones.}

Conozca nuestra práctica de Arbitraje

Escanee este código con la cámara de su celular

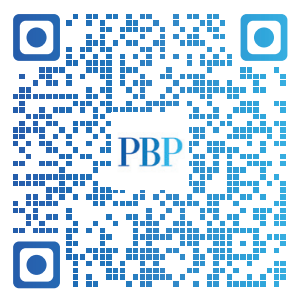

WWW.pbplaw.com

in Pérez Bustamente \& Ponce (PBP)

Yapbplaw

\section{Quito}

Av. República de El Salvador N36-140

Edificio Mansión Blanca

PBX: 024007800

+59323827640 al 48

\section{Guayaquil}

Av. Francisco de Orellana.

Edificio Las Cámaras,

Torre B, oficina 904.

$+59343707960$ 
